\title{
The Application of Visualization in English Teaching
}

\author{
Wenjun Liu \\ Jiangxi University of Applied Science \\ Nanchang, China
}

\begin{abstract}
Most of students from non-English speaking countries have a preference on choosing English as a second language because English has been one of the most popular and important language now which is widely applied in not only daily communication but also in commercial trade. Therefore, English teaching and learning tends to be an essential part as it may determine the result to some extent. A suitable and acceptable method for teaching and learning especially its attraction to students is the key. In this dissertation, some existing methods and a new visualized English teaching and learning method will be discussed in order to make English learning easier.
\end{abstract}

Keywords-Teaching methods; Multimedia; Visualization; Prototype; Evaluation

\section{INTRODUCTION}

English is considered as an official language for a long time. Learning English is presenting an increasing trend especially in non-English speaking countries as to keep pace with the modern world. As a result, how to teach English and how to explore more effective methods for teaching also turn to be an eye catching topic. Besides traditional English teaching methods (mainly refers to writing on blackboard and explain it to students), various approaches appear during these years, among which multimedia technique is a popular and flexible method. Applying multimedia to English teaching is the inevitable trend.

Visualization is not a new concept for people. However, it is mainly used in computer field for a long time while rarely concerns other areas. As a result, the investigation on the use of visualization in English teaching is a new research area.

\section{OVERVIEW ON EXISTING ENGLISH TEACHING METHODS}

The main aim of this project is to investigate the advanced method of visualization for the use of teaching English to help people learn English easier. The whole project includes 7 objectives and 15 tasks, through which it involves producing a visualization product prototype for English teaching based on findings from literature and requirements gathering. Macromedia's popular application Flash has redefined the way web developers approach web design, especially compared to traditional methods like GIF animations.

In order to get requirements, a survey is required. Ensuring the group of people who will be chosen to help the investigation strictly according to the Ethical Approval is the first important step. The objects would mainly focus on students for whom English is not the first language and members of staff responsible for English language teaching in university. Interviews, questionnaire and focus group are candidate methods for the results to support the process of survey. In this project, a visualized product together with a section of interactivity with students will be investigated in order to achieve visualization for English teaching and learning. The world holds over 7000 languages, and most exist within only a small geographic area; even most of the top 100 are limited to a small number of countries or even a single state.

Teaching English therefore involves not only helping the student to use the form of English most suitable for his purposes, but also exposure to other forms of English (e.g. regional forms/ cultural styles) so that the student will be able to discern 'meaning' even when the words/grammar/pronunciation may be quite different to the form of English with which he has become more familiar. For various reasons, there is a very interesting phenomenon about English learning in China-Chinglish. Chinglish (slang) is a portmanteau of the words Chinese and English.

English is not native language for Chinese students Second language acquisition is the process by which people learn languages in addition to their native language (s). It is claimed that the future potential for improvements lies in the "hard fun" cited by the MIT Media Lab as a sugar-coat of the medicine of study (work). ( Resnick, M. , 2004 )

In case of the relevant and clear goal and existing textbook, the old structure of education still plays an important role, not only to the child but also the adult learner. However, traditional education has a lack of individual training for students with different levels of study, and a qualified researcher or professor may well fail to be an employable lecturer. (Neal, L., Miller, D., 2005)

Teaching methods have a long history and relate to the questions, "What is the purpose of education?" and "What are the best ways of achieving these purposes?" For much of human history, educational method was largely unconscious. Pedagogy is usually the different ways a teacher can teach. A lesson plan may be carried out in several ways: Questioning, explaining, modeling, collaborating, and demonstrating. (Palmer)

Language teaching practice often assumes that most of the difficulties that learners face in the study of English are a consequence of the degree to which their native language 
differs from English (a contrastive analysis approach). A fundamental assumption that governs the study of English and the study preparation of English teachers is that "the subject of English is always the site of subjectivity" (Humm 1989, 39).

\section{EXISTING MODERN TEACHING METHODS AND MULTIMEDIA}

For the short of old fashioned education, some new and modern types of education are developed to either improve efficiency or provide a chance for learners to study by themselves after class. Distanced learning, which is aimed for "a richer and more engaging educational experience" must be the most familiar type for people. (Neal, L., Miller, D., 2005) People especially students under 18 are natural with a low consciousness to themselves. "Fig. 1"

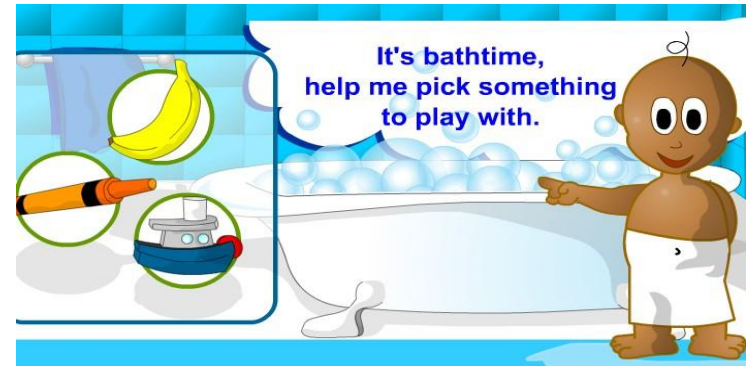

Fig. 1. Demonstrate of a simple English game.

When we were still a child, the kind of combination of game and learning is used to help child to speak, to walk, to communicate and so on. Regardless of age or gender, games are always a vital part of life, as people love games. If it could be like gaming, studying itself would never be so boring or difficult. (Piaget, J. 1932)

Due to this fact, a large number of audio-visual games are developed for class teaching, ranging from role-play, pair-work, act and say, to gesture and pose.

Multimedia (Lat. Multum + Medium) is media that uses multiple forms of information content and information processing (e.g. text, audio, graphics, animation, video, interactivity) to inform or entertain the (user) audience. According to Sweller, the generative theory of multimedia learning is basically concerned with how learners integrate verbal and video information. Nowadays multimedia is being used increasingly in school to enhance the quality of teaching and learning. "Fig. 2"

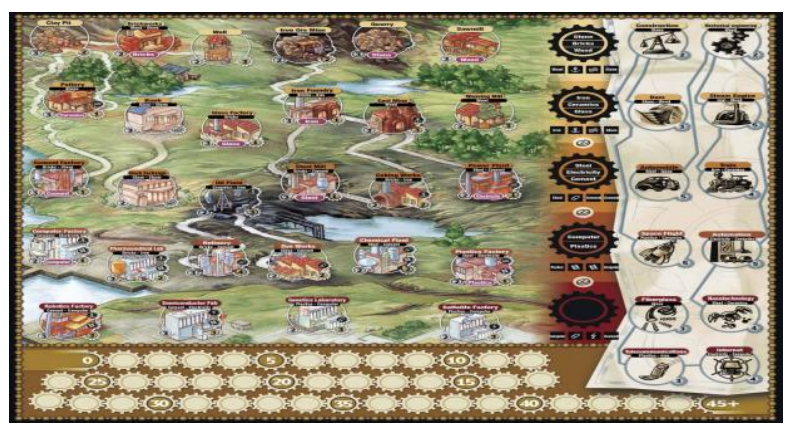

Fig. 2. Demonstrate of a more complicated game.
School is a necessary place for people to study all over the world as it provides systemized education and facilities needed by students. But the problem with most corporate adult learning programs is that they are just like school. It works against the way the brain wants to learn.

A stimulating, active, challenging, interesting, engaging environment leads to best learning. It is how the brain works. Forcing people to sit in a chair and listen (or read) dry, formal words (with perhaps only a few token images thrown in) is the slowest, least effective, and most painful path to learning. "Fig. 3"

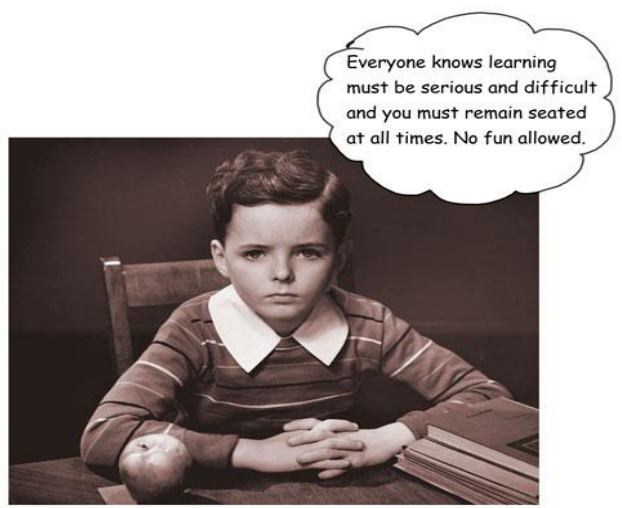

Fig. 3. An assistant picture.

Multimedia presents information, shares ideas and elicits emotions. It enables you to see, hear, and understand the thoughts of others. In other words, it is a form of communication. Some of the attributes of multimedia are:

- Multimedia can extend the sensory content of learning environment through sound, music, video, animation and graphics;

- Multimedia can provide multiple, multi sensory learning contexts;

- Multimedia offers a safe environment for risk taking, experimentation, exploration, and problem solving.

- Students are encouraged advancing and commenting on the goal in their own paces with the suitable test, but not taught among a lot of different students in the classroom.

- According to Prensky, the greatest advantage is uncertainty stimulates the interest.

As it takes the most vivid one but at the time of the environment not fully utilized, the multimedia is important to improving the language level. So, it may get the second generation of language efficiently. Similar to online conversation, this multimedia means and simulated language acquisition process have been proved to be non-threatening in terms of students' inhibitions of speaking a new language within classrooms. (Hudson 2002). 


\section{VisUALIZATION}

The world changes so quickly it is hard to keep up. New inventions and innovations alter the way we live. People's values, attitudes, and beliefs are changing. Visualization technology is just fitting such circumstance and could give a good chance for students to concentrate on their study more and enjoy in their study.

Visualization is one kind of multimedia and it could be defined in three parts: psychology, spiritual disciplines and technology. Visualization can refer to the following concepts:

Psychology:

- The process of creating internal mental images (internal visualization and imagination).

- Spatial visualization ability.

Spiritual disciplines:

- The engaging of one's imagination within the bodymind to effect changes in consciousness.

Technology:

- Graphic visualization, as in any technique for creating images, diagrams, or animations to communicate any message.

- Scientific visualization, an area of computer graphics that is concerned with the presentation of potentially huge quantities of laboratory, simulation or abstract data to aid cognition, hypotheses building, and reasoning.

- Knowledge visualization, a sub discipline of Information Design and Instructional Message Design.

- Product visualization, visualization software technology for manufacture of components and large assemblies of products.

- Music visualization, a feature found in some media player software applications.

In this project, visualization is defined according to the first definition of Technology, graphic visualization.

Multimedia teaching method has been used in English teaching wider and wider. It has contributed a lot to higher teaching quality. Here we have some questions. What is missing in our English class? What do we want most? What is the most difficult? What problem do our teachers want to solve when using modern information technology? With the powerful functions of the multimedia computers, students can talk with the virtual characters set by the computer. At the same time, students can correct their own mistakes according to the judge of the computers, which is beneficial to improve their ability of communication. (Nunan, David. (2005)

Multimedia teaching method belongs to CAI (computeraided instruction) in substance, and we can heighten efficiency substantially, which is a kind of trend. We should make best use of its advantages and bypass its disadvantages. Applying visualization to teaching can increase student's interest, and it is able to expand knowledge and get joy at the same time. As a live communicating tool, instead of solely hurrying through test questions that fulfill no tenet of language acquisition (as shown below), a more various and interesting pattern is more acceptable for learners. "Fig. 4"

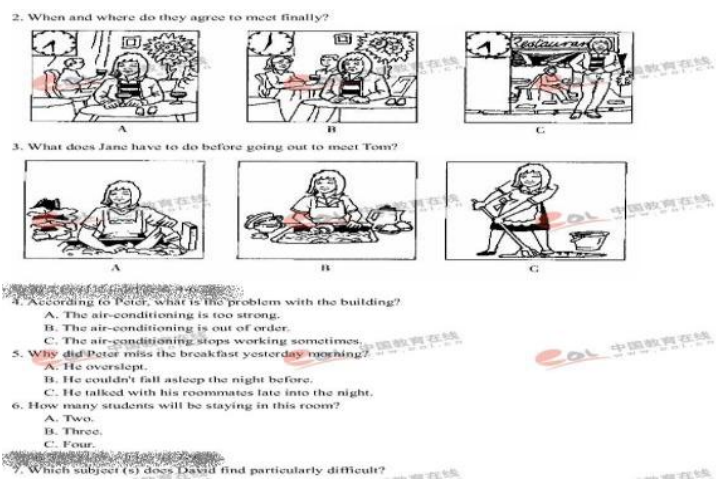

Fig. 4. A traditional English test example with graph.

\section{REQUIREMENTS GATHERING}

Being the most commonly seen software, the ones called "English speaking king" ,"Crazy English Big bites" are multi-functional with the four basic skills of reading, listening, speaking. Some others, such as "the American talking mate" "easy English words and speaking" are more specialized in vocabulary and oral speaking. The first function of the software is to read, details and explanation will help students to understand the whole article with the translation. The second main function in the software is dictating. A language system is not separately built, no single skill as speaking, listening, reading should be fostered alone.

User-centered interaction design is to ensure that the system is designed to support the user, minimize error and promote productivity and performance gains. The user interface (or Human Machine Interface) is the aggregate of means by which people (the users) interact with a particular machine, device, computer program or other complex tool (the system). In general, the term "affective" refers to producing an emotional response. In this design, software based on visualization for English learning will be produced. It is a new try on combining images, diagrams, audio, video and animations as well as a testing together. It focuses on interesting and effective aspects.

There are two aims. One aim is to understand as much as possible about the users, their work, and the context of that work, which is called "identifying needs". The second aim is to produce, from the needs identified, a set of stable requirements that form a sound basis to move forward into thinking about design. design.

Here are some kinds of requirements for a prototype

- Functional requirements

- Data requirements 
- Environmental requirements

- User requirements

- Usability requirements

In order to gather requirements efficiently, Dategathering techniques are commonly chosen. However, this technique includes 5 different forms: questionnaires; interviews; focus groups and workshops; naturalistic observation; studying documentation. In order to get extensive requirements, a focus group participated by students and two interviews to English teachers are held for help. 5 college students from different countries including Poland, China and India are collected to take part in the focus group. Two teachers in the interview are Angela from China and Marta from Poland.

In a word, the main requirements for visualized English learning software are summarized as follows:

- Effective way needs the syllable based on each name in order to pronounce the prophecy of forming. Using the cognition of the vocabulary to form sentences actually for the natural practice, concrete context expression way.

- Preview the comment that is forced and planned.

- Interesting interaction need to advance motive force.

\section{PROTOTYPE DESIGN AND EVALUATION}

Concerning Englishmen's relevant software, there are small online flashing products of grammar that one enormous quantity is suitable for the vocabulary and learn. The ability amalgamates the intricate and educational key element of stocking a kind of product and removes this crowd's pressure of every day and notifies them with the low cost it may be capable.

A prototype is something that is representative of a category of things. Prototype is the process of quickly putting together a working model (a prototype) in order to test various aspects of a design, illustrate ideas or features and gather early user feedback. The prototyping model is a software development process that begins with requirements collection, followed by prototyping and user evaluation.

Adobe flash and dreamweaver are needed in order to finish the prototype. Actually, this product is combined with graph, sound, visualization and educational game together. It is satisfying with students' interest, study and exiting aspects. Interface chosen here is bright, lovely and lively with cartoon images.

The prototype is divided into three parts.

Firstly, an English diagram video will be designed by Adobe Flash. The video will show students a short story or a theme with captions. "Fig. 5"

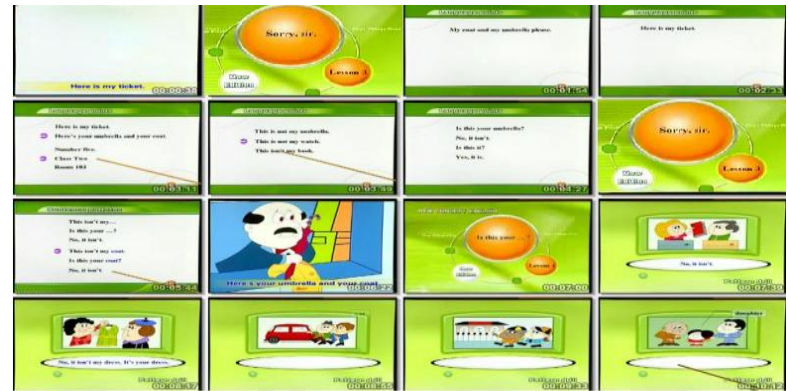

Fig. 5. Group picture of video graph.

Secondly, some test questions according to the content of the diagram will be made, which is listed in the form of single or multiple choices; dreamweaver is used to set up a website to embed the video and test together. "Fig. 6"

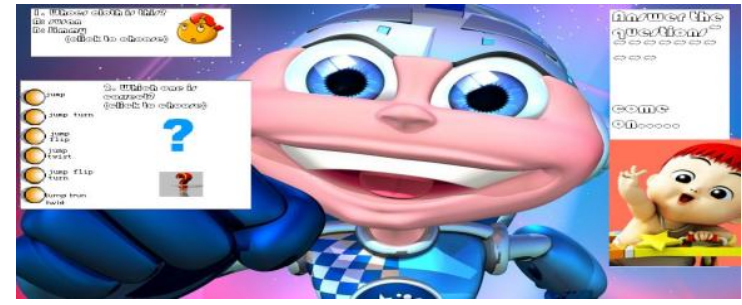

Fig. 6. Illustration of a new lovely English test.

Thirdly, when students pass the second part, they can come to the third part - educational games. The first game is a simple and interesting one called a finger-guessing game. Actually, this is just a catabolic step for students to relax first. "Fig. 7"

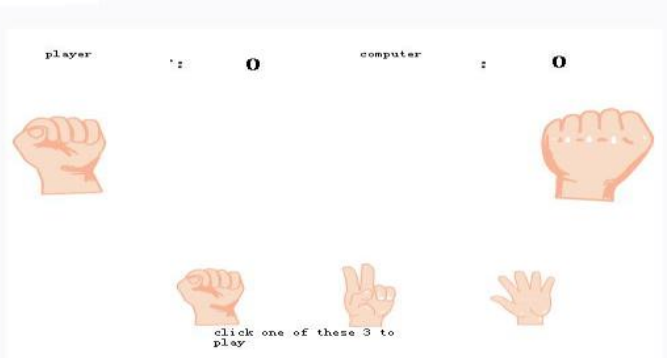

Fig. 7. Game graph in the video.

Second game is a words game companied with music and students need to press the right key when different words drop down following the tempo of music. "Fig. 8"

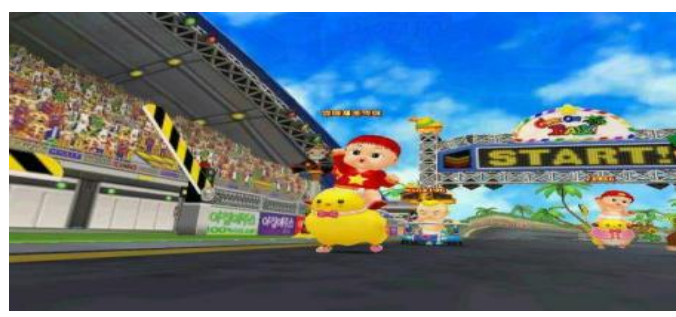

Fig. 8. Game start graph. 


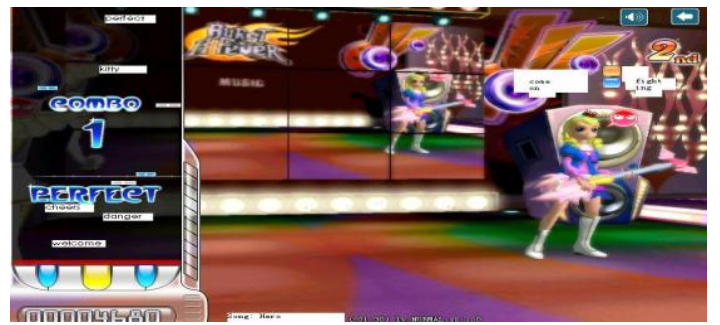

Fig. 9. Graph in gaming.

Actually, evaluation is for designers to have a test of the usability of the product and satisfaction of users. Evaluation is needed to check that users can use the product and like it. "Fig. 9"

Questionnaire is used for evaluation. The main process for a questionnaire design is as follows:

What we choose is in the form of ranking system (1-10) combined with a statement with tick-box style answers ("strong agree", "agree", "disagree", "strong disagree", "neither agree or disagree");

Make sure of the investigation scope aiming to the purpose of your prototype. State the specific questions.

Pay attention to use the accurate, proper words and clear, splendid outlook.

This software is a novelty try for multimedia English learning. It could be inferred through the investigation and questionnaire to people. As a result, it is undoubted that this is a field worthy exploring.

\section{CONCLUSION}

Harmer (1991) says, "The teacher plays multiple roles in communicative activities-as controller, as assessor, as organizer, as prompter, as participant and as resource." So teachers enrich important embodiment of income in the class which can utilize interest and initiative of students and train themselves to study. Regrettably, most teachers can not realize and understand this education concept thoroughly. So teachers must be willing to put aside their own egos and transfer the learning focus from themselves to their students (Frizler, 1995). Teachers should exert their effort to become "a resource of information" rather than "the source of information" (Linder, 2000).

Under having constructive research environments, should include to design not only teach the goal to educate analyzed but also create a certain scene suitable for the learner to study. We can say that the teaching method of the multimedia is made and stood and become one to create such good tool of research scene in English teaching. But a pity one is some teachers have some misunderstanding to multimedia English teaching. (Bimber, Oliver, 2005) The teacher deals with the minor matter and neglects essence.

No matter how strong the modern education skill is, this is only a kind of technology, and it only offers a kind of possibility. This kind of technology is not red panacea of forest, people can't depend on excessively, otherwise we will lose and sanction. Students are that a subject teacher is an advisor. Why well does a good teacher that he can encourage them and study the interesting sympathetic response of wanting and causing students of research. Even this remains a teacher's instruction, it is different basically.

In a word, the teaching method of the multimedia is CAI (computer-assisted instruction). Its unfavourable conditions are that we should fully utilize its advantage and branch road. Certainly it cannot replace all other teaching methods, but we can use several kinds of methods together in a lesson. Only we can use the advanced education theory under the background of quality-oriented education, and we can be satisfied with the goal of English teaching through the modern education skill of rational utilization. In the future, people could keep researching on this field as a long-term topic and make a quite great progress.

\section{REFERENCES}

[1] Harmer, J. (1991). The Practice English Language Teaching. Longman.

[2] Kristeva, J. [19771 1980. Desire in language. Trans. L. S. Roudiez. New York: Columbia University Press.

[3] Mayer, R.E. (2001). Multimedia Learning. Cambridge: Cambridge University Press. ISBN 0-521-78239-2.

[4] Nielsen J.\& Mack Robert L.(Edited c1994). Usability Inspection Methods. Willey.

[5] Renandya, W. A. (2002) Methodology in language teaching. New York: Cambridge University Press.

[6] Shetzer H. \& Warschauer M. 2000, “ An electronic literacy approach to network-based language teaching" in Network-based Language Teaching: Concept and Practice. Cambridge

[7] Yvonne Rogers, Helen Sharp, Jenny Preece.2002. Interaction Design: beyond human computer interaction. John Wiley \% Sons Inc: USA.

[8] Dingsdale, Paul(2000). Multimedia lets teachers turn classroom into a dimension of sight, of sound and of mind. Available at: http://www.usc.edu/hsc/info/pr/1vol6/602/media.html (Accessed on 23 April)

[9] Flash Introduction. Available at http://www.tizag.com/flashTutorial/ (Accessed on 6 May)

[10] Guo Fang. A Comparison Between Online English Language Teaching and Classroom English Language Teaching. Available at: http://www3.beiwaionline.com/tutorgarden/temp5/guofang.ht $\mathrm{m}$ (Accessed on 4 May)

[11] 'How To Prepare For A Questionnaire'(2005) Available from:http://zhidao.baidu.com/question/1589858.html?si=1 (Accessed on 10/10/2007)

[12] Lynch, J. Patrick. Teaching with Multimedia. http://jeffline.jefferson.edu/CWIS/OAC/medibytes/spring93/ medibytes_article1.html (Accessed on 24 April)

[13] Traditional English teaching methods challenged. Available at: http://www.cctv.com/lm/134/21/85858.html (Accessed on 4 May)

[14] Clark, R.C., Mayer, R.E. (2002). e-Learning and the Science of Instruction: Proven Guidelines for Consumers and Designers of Multimedia Learning. San Francisco: Pfeiffer. ISBN 0-7879-6051-9.

[15] Engyold, k.j.\& Hughes,j.1 (2006) A model for a multifunctional teaching system. Volume 10, Issue 6; Pages: $339-342$. New York: ACM Press.

[16] Gong Wu, Zhou Wen-juan(2007) Thinking on the Application of Multimedia into College English Teaching. Volume 5, No.4 (Serial No.43)

[17] Guo Yali, " How can teachers positively affect students' motivation?" Teaching English in China, Vol. 26 No. 1: 45-48, March 2003 
[18] Harmer, J. (2003) Popular culture, methods, and context ELT J 2003 57: 288-294

[19] Mayer, R., \& Moreno, R.(1998). A split-attention effect in multimedia learning: Evidence for dual processing systems in working memory. Journal of Educational Psychology, 90,312-320. 